\title{
Stay-at-Home Stocks Versus Go-Outside Stocks: The Impacts of COVID-19 on the Chinese Stock Market
}

\author{
Dehua Shen $^{1}$ (D) Wei Zhang ${ }^{1}$ \\ Published online: 31 August 2020 \\ (c) Springer Japan KK, part of Springer Nature 2020
}

\begin{abstract}
This paper investigates the distinct market reactions to the COVID-19 outbreak by focusing on two groups of stocks in the Chinese stock market, i.e., the stay-at-home (SAH) stocks, and the go-outsides (GO) stocks. The empirical results mainly reveal that: (1) for the GO stocks, there exists a significantly negative return on the event date and the cumulative abnormal return reveals reversal pattern; (2) for the SAH stocks, no significantly negative return is observed on the event date and the cumulative abnormal return continues to increase; and (3) generally speaking, the reaction of the GO stocks supports the price pressure hypothesis, while the reaction of the $\mathrm{SAH}$ stocks supports the information diffusion hypothesis. Our results suggest that investors in the Chinese stock market could moderately interpret the good news but underestimate the bad news.
\end{abstract}

Keywords COVID-19 - Information diffusion · Price pressure · Investor sentiment · Chinese stock market · Event study

\section{Introduction}

Current literature has documented that major events, e.g., natural disasters (Bourdeau-Brien and Kryzanowski 2017), terrorist attacks (Chesney et al. 2011; Papakyriakou et al. 2019), political crises (Berkman et al. 2011), sports events (Chang et al. 2012; Edmans et al. 2007), TV series finales (Lepori 2015; Zhang et al. 2017), and aviation disasters (Kaplanski and Levy 2010), would have material impacts on the stock market. Meanwhile, the findings on the market reaction to the recommendations and media coverage (news hereafter) mainly summarize two hypotheses for the

Dehua Shen

dhs@tju.edu.cn

Wei Zhang

weiz@tju.edu.cn

1 College of Management and Economics, Tianjin University, No. 92 Weijin Road, Nankai

District, Tianjin 300072, People's Republic of China 
underlying mechanisms. The information diffusion hypothesis (IDH) claims that if the news contains fundamental information, the changes in prices should be persistent and no price reversal would be observed. Conversely, the price pressure hypothesis (PPH) argues that the positive (negative) news only generates temporary buying (selling) pressure and the changes in prices will revert to the fundamental value. The recent outbreak of COVID-19 provides us with a unique setting to simultaneously investigate its impacts on stocks with distinct characteristics. In particular, we consider the event of the Wuhan lockdown on 23 January 2020 as a nationwide negative shock to the Chinese stock market and examine whether its impact on the stock market is driven by IDH and PPH.

Our empirical strategy is organized as follows. First, we construct two groups of stocks by considering whether the listed firms' main business is increased or decreased due to the lockdown event, i.e., the stay-at-home stocks (SAH stocks) and the go-outsides stocks (GO stocks). In particular, the SAH stocks mainly contain the stocks in the categories of Cold Chain Logistics, Beer, Dairy, Webcast, Cloud Office, Cloud Games, and Online Education and the GO stocks consist of the stocks in the categories of Sports, Ride-hailing, and Travel. Generally speaking, the lockdown event is beneficial to the SAH stocks and detrimental to the GO stocks. Second, we employ the standard event study methodology to investigate the impacts of the lockdown event on the changes in prices of the SAH stocks and the GO stocks, respectively. The empirical findings mainly reveal that: for the GO stocks, there exists a significantly negative return on the event date and the cumulative abnormal return reveals reversal pattern; for the SAH stocks, no significantly negative return is observed on the event date and the cumulative abnormal return continues to increase.

We mainly contribute to the literature in two aspects. In the first place, we are the first to investigate the underlying mechanisms of why the stock market is influenced by the COVID-19 outbreak. In particular, our results show that the two influencing channels co-exist, i.e., the prices change of SAH stocks is driven by information diffusion, while the prices change of the GO stocks is driven by price pressure. In that sense, this paper deepens our understanding of the interdependence between natural disasters and sock market dynamics (Bourdeau-Brien and Kryzanowski 2017; Shan and Gong 2012). In a concurrent paper, Al-Awadhi et al. (2020) show that the daily growth in total confirmed cases and in total cases of death caused by COVID-19 is negatively related to the stock returns, while they fail to provide any explanations on their finding. In the second place, contrary to the prevailing view that the Chinese stock market is driven by a large number of irrational individual investors who are subjected to psychological biases (Li et al. 2018; Zhang et al. 2016a), our findings reveal that the prices of the $\mathrm{SAH}$ stocks continue to increase suggesting that the investors in the Chinese stock market correctly interpret the impacts of the lockdown event on the fundamentals of the SAH stocks. Generally speaking, these findings suggest that investors are more rational during the COVID-19 outbreak period.

The remainder of this paper is organized as follows. Section 2 summarizes the related literature and develops the research hypotheses. Section 3 describes that data and research methodology, i.e., the event study method. Section 4 presents the main findings and Sect. 5 concludes. 


\section{Related Literature and Hypotheses Development}

Our paper aligns with two streams of literature. We first review the literature on the impacts of major events on market dynamics in Sect. 2.1 and then discuss the empirical findings summarizing the underlying mechanisms and develop our research hypotheses in Sect. 2.2.

\subsection{Impacts of Major Events on Market Dynamics}

The literature on the impacts of major events on market dynamics usually considers the event as a shock to investor sentiment. Relating the outcomes of the sports to sudden changes in investor sentiment, Edmans et al. (2007) document a significant loss effect after international soccer, cricket, rugby, and basketball games and this loss effect is more pronounced in small stocks and in more important games. Kaplanski and Levy (2010) find evidence of a significant negative event effect with an average market loss of more than $\$ 60$ billion per aviation disaster. Employing the event-study methodology, Papakyriakou et al. (2019) show that the stock market decline significantly on the terrorist attack day and on the following trading day. This event-based measurement of the shock to investor sentiment has gained increasing popularity and is used in various empirical studies, e.g., Bourdeau-Brien and Kryzanowski (2017), Berkman et al. (2011), Chang et al. (2012), Chesney et al. (2011), Lepori (2015), among others. Generally speaking, all the empirical studies share the same research philosophy, i.e., "major event-investor sentiment/mood-impacts on the stock market". In this paper, we also consider the outbreak of the COVID-19 as the sentiment shock to investors and examine its impacts on the Chinese stock market.

\subsection{IDH, PPH and Hypotheses Development}

Existing literature has documented two hypotheses to explain the market reaction to recommendations and media coverage. Focusing on the analysts' recommendations published in the "Dartboard" column of the Wall Street Journal, Barber and Loeffler (1993) show that the positive abnormal return on the announcement is partially reversed within 25 trading days and then conclude that positive abnormal return on the announcement of the recommendations is a result of both buying pressure and information diffusion. With the post-event estimation methodology, Albert and Smaby (1996) further show that the positive abnormal return on announcement displays no significant reversal and conclude that the abnormal return is driven by information diffusion. Conversely, Liang (1999) finds that investors following the recommendations lose $3.8 \%$ on a risk-adjusted basis over a 6-month holding period and suggests that abnormal returns and trading volume around the announcements are mainly driven by noise traders. Recently, by investigating the market reaction to Internet news mentioned in the column of "Ahead of Stock Market" of the NetEase, Zhang et al. (2016b) conclude that both the information diffusion hypothesis (IDH) 
and price pressure hypothesis (PPH) could explain the significantly positive abnormal return and excessive trading volume around the announcement date.

To sum up, IDH argues that price changes should be persistent and no price reversal would be expected and PPH suggests that price changes will revert to the fundamental value in a short period. Since the focus of this paper is to investigate the impacts of COVID-19 on the Chinese stock market connecting to the IDH and $\mathrm{PPH}$, we divide our sample stocks into two groups, i.e., the SAH stocks and the GO stocks. Besides, it is widely documented that natural disasters will have negative impacts on the stock market (Bourdeau-Brien and Kryzanowski 2017; Shan and Gong 2012; Al-Awadhi et al. 2020). Therefore, we propose our first hypothesis:

Hypothesis 1 The COVID-19 outbreak has a negative impact on both the SAH stocks and the GO stocks.

As we mentioned previously, the rationale of dividing sample stocks into the SAH stocks and the GO stocks is that the lockdown event is beneficial to the SAH stocks and detrimental to the GO stocks. Therefore, if the IDH holds, the price changes of the SAH stocks will go up and the price changes of the GO stocks will continue to drop, and vice versa. Therefore, we put forward the following hypotheses:

Hypothesis 2a If the IDH holds, the price changes of the SAH stocks will go up and the price changes of GO stocks will continue to drop.

Hypothesis $2 \mathrm{~b}$ If the PPH holds, both the price changes of the SAH stocks will drop and the price changes of GO stocks will go up.

\section{Data and Methodology}

In this section, we first define the concept of the stay-at-home stocks and the gooutside stocks from the perspective of whether the listed firm's production (service) is consumed (delivered) at home or going outside. The standard event-study is then performed to examines the impacts of the COVID-19 on the SAH stocks and GO stocks, respectively.

\subsection{Stay-at-Home Stocks and Go-Outside Stocks}

To empirically investigate the impacts of COVID-19 on the Chinese stock market, we focus on two groups with significant distinctions, i.e., the stay-at-home stocks and the go-outside stocks. The definitions of these groups are mainly based on the assumption that whether the listed firm's production (service) is consumed (delivered) at home or going outside. In particular, the stay-at-home stocks include stocks in the category of Cold Chain Logistics, Beer, Dairy, Webcast, Cloud Office, Cloud Games, and Online Education and the go-outsides stocks in the category of Sports, Ride-hailing, and Travel. The definitions of the categories, the capital data including the individual stock 
returns and the market returns are obtained from the iFinD Financial Data Terminal. "Appendix A" reports the details of the stocks in each category. The sample period is from 1 January 2019 to 30 April 2020 covering the estimation period of [ $-125,-26]$ and the post-event period of $[1,60]$.

\subsection{Event-Study Methodology}

To empirically investigate the impacts of the lockdown event on the Chinese stock market, we implement the standard event-study analysis (Brown and Warner 1985; Boehmer et al. 1991; Kolari and Pynnönen, 2010; Zhang et al. 2016b; Papakyriakou et al. 2019). We estimate the CAPM model using individual stock returns in the SAH stocks group and GO stocks group as the dependent variable and the CSI 300 market index return as the independent variable. In line with Barber and Loeffler (1993) and Zhang et al. (2016b), we choose the trading days of $[-125,-26]$ as the estimation period. Specially, we estimate the following regression equation:

$$
R_{i t}=\alpha_{i}+\beta_{i} R_{m t}+\varepsilon_{i t} \quad t=-125, \ldots,-26
$$

where $R_{i t}$ is the stock returns in the SAH stocks group and GO stocks group for stock $i$ on day $t, R_{m t}$ is the CSI 300 market index return on day $t, \alpha_{i}$ and $\beta_{i}$ are the estimated coefficients, and $\varepsilon_{i t}$ is the residual. We define the abnormal returns (AR) for individual stock as the difference between actual returns and expected returns. We further employ the estimated coefficients, i.e., $\hat{\alpha}_{i}$ and $\hat{\beta}_{i}$, from Eq. (1) to calculate the abnormal returns for the trading days of $[-25,60]$ with the following equation:

$$
A R_{i t}=R_{i t}-\left(\hat{\alpha}_{i}+\hat{\beta}_{i} R_{m t}\right) \quad t=-25, \ldots, 60
$$

where $A R_{i t}$ is the abnormal returns for stock $i$ on day $t$. We then calculate the average abnormal return $\left(A A R_{t}\right)$ on day $t$ and the cumulative abnormal return from date $t_{1}$ to date $t_{2}\left(C A R\left(t_{1}, t_{2}\right)\right)$ with the following equations:

$$
\begin{gathered}
A A R_{t}=\frac{\sum_{i=1}^{N} A R_{i t}}{N} \quad t=-25, \ldots, 60 \\
C A R\left(t_{1}, t_{2}\right)=\sum_{t=t_{1}}^{t_{2}} A A R_{t} \quad t_{1}=0, t_{2}=60
\end{gathered}
$$

where $N$ denotes the number of stocks in the SAH stocks group and GO stocks group.

\section{Main Results}

\subsection{Graphical Illustration of Overall Findings}

For a clear illustration, we first present the graphical illustration of the overall findings on average abnormal return $(A A R)$ and cumulative abnormal return $(C A R)$ in 


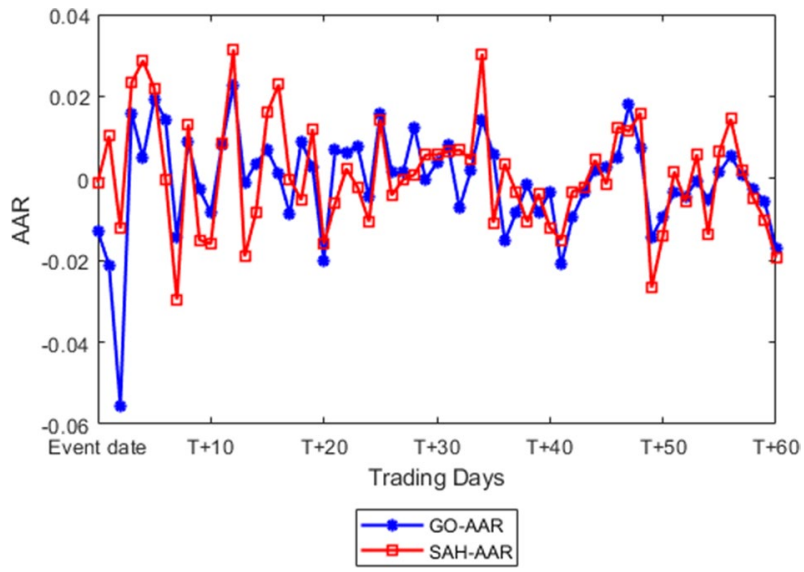

Fig. 1 GO-AAR and SAH-AAR

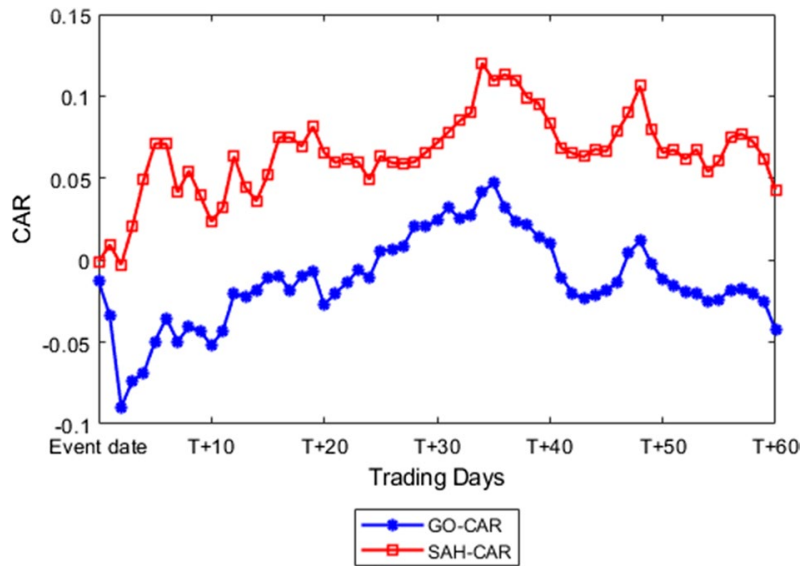

Fig. 2 GO-CAR and SAH-CAR

Figs. 1 and 2, respectively. As is clearly illustrated in Fig. 1, the outbreak of the COVID-19 has a negative impact on the GO stocks while the impact is less pronounced for the SAH stocks. Table 1 reports that, on the event date, the AAR for GO stocks is -0.0128 (significant at $1 \%$ level with $p$-value $<0.01$ ) and the $A A R$ for SAH stocks is -0.0010 (insignificant with $p$-value $>0.1$ ). The negative impact is consistent with previous findings on the impacts of natural disasters and terrorist attacks on stock returns (Bourdeau-Brien and Kryzanowski 2017; Chesney et al. 2011; Papakyriakou et al. 2019) and supports our first hypothesis. Figure 2 illustrates the $C A R$ starting from the event date to the post-60 trading date. We find that the mean value of $C A R$ for SAH stocks is $0.0701 \%$ and the mean value of $C A R$ for GO stocks is $-0.0698 \%$, which are highly correlated with the correlation coefficient is 0.5923 and $p$-value $<0.01$. 
Table 1 AAR and CAR around the event date

\begin{tabular}{|c|c|c|c|c|c|c|c|c|}
\hline \multirow[t]{3}{*}{ Date } & \multicolumn{4}{|c|}{ Panel A: SAH stocks } & \multicolumn{4}{|c|}{ Panel B: GO stocks } \\
\hline & \multicolumn{2}{|l|}{ AAR } & \multicolumn{2}{|l|}{ CAR } & \multicolumn{2}{|l|}{ AAR } & \multicolumn{2}{|l|}{ CAR } \\
\hline & Mean & $P$ value & Mean & $P$ value & Mean & $P$ value & Mean & $P$ value \\
\hline-25 & 0.0095 & 0.0000 & 0.0095 & 0.0000 & 0.0037 & 0.0037 & 0.0050 & 0.0037 \\
\hline-10 & 0.0062 & 0.0000 & 0.0353 & 0.0000 & 0.0030 & 0.0843 & 0.0332 & 0.0000 \\
\hline-5 & -0.0009 & 0.5549 & 0.0395 & 0.0000 & -0.0017 & 0.3717 & 0.0346 & 0.0001 \\
\hline-4 & -0.0068 & 0.0001 & 0.0327 & 0.0001 & -0.0054 & 0.0045 & 0.0293 & 0.0009 \\
\hline-3 & -0.0083 & 0.0000 & 0.0244 & 0.0044 & -0.0100 & 0.0001 & 0.0192 & 0.0401 \\
\hline-2 & 0.0011 & 0.5199 & 0.0255 & 0.0029 & -0.0058 & 0.0047 & 0.0134 & 0.1551 \\
\hline-1 & -0.0062 & 0.0031 & 0.0193 & 0.0285 & -0.0096 & 0.0000 & 0.0038 & 0.6950 \\
\hline 0 & -0.0010 & 0.6683 & 0.0183 & 0.0553 & -0.0128 & 0.0000 & -0.0090 & 0.3560 \\
\hline 1 & 0.0103 & 0.0087 & 0.0286 & 0.0101 & -0.0212 & 0.0000 & -0.0302 & 0.0030 \\
\hline 2 & -0.0122 & 0.0008 & 0.0164 & 0.1934 & -0.0555 & 0.0000 & -0.0857 & 0.0000 \\
\hline 3 & 0.0234 & 0.0000 & 0.0398 & 0.0034 & 0.0157 & 0.0000 & -0.0700 & 0.0000 \\
\hline 4 & 0.0287 & 0.0000 & 0.0685 & 0.0000 & 0.0050 & 0.0174 & -0.0650 & 0.0000 \\
\hline 5 & 0.0220 & 0.0000 & 0.0905 & 0.0000 & 0.0194 & 0.0000 & -0.0456 & 0.0007 \\
\hline 10 & -0.0159 & 0.0000 & 0.0428 & 0.0015 & -0.0084 & 0.0000 & -0.0479 & 0.0004 \\
\hline 20 & -0.0159 & 0.0000 & 0.0849 & 0.0000 & -0.0201 & 0.0000 & -0.0163 & 0.2826 \\
\hline 30 & 0.0059 & 0.0008 & 0.0910 & 0.0000 & 0.0038 & 0.1985 & 0.0281 & 0.1036 \\
\hline 40 & -0.0120 & 0.0000 & 0.1028 & 0.0000 & -0.0032 & 0.1191 & 0.0143 & 0.4531 \\
\hline 50 & -0.0138 & 0.0000 & 0.0850 & 0.0000 & -0.0093 & 0.0005 & -0.0079 & 0.6984 \\
\hline 60 & -0.0194 & 0.0000 & 0.0620 & 0.0010 & -0.0171 & 0.0000 & -0.0388 & 0.0840 \\
\hline
\end{tabular}

This table reports the average abnormal return $(A A R)$ and the cumulative abnormal return $(C A R)$ around the event date. The definitions of the $A A R$ and $C A R$ are given in Eqs. (3) and (4). The starting date for the $C A R$ is -25 . The "Mean" denotes the $A A R$ and $C A R$ on certain date. The " $P$ value" denotes the $p$ value of the t-test based on Kolari and Pynnönen (2010)

\subsection{Event-Study Analysis: Overall Findings}

To observe the evolution of the piece changes of the GO stocks and the SAH stocks, we tabulate the $A A R$ and $C A R$ (starting from -25 to 60 trading date) in Table 1. In particular, we do not observe significant $A A R$ and $C A R$ for both the GO stocks and the SAH stocks two days before the event date. However, as shown in Table 1, the COVID-19 has a negative impact on the GO stocks on the event date, while no significantly negative return is observed for the SAH stocks. Focusing on the CAR starting from the event date to the post-60 trading date in Table 2, the results show that the $C A R$ for the SAH stocks are always significantly positive, thus support the IDH. While for the GO stocks, the negative impact persists in the following 20 trading days and then shows a reversal pattern (the positive or negative CAR becomes insignificant for the interval of $[0,30],[0,40]$ and $[0,50])$. These findings suggest that the outbreak of the COVID-19 only serves as a negative shock to investors, who does not realize that the COVID-19 will have some material impacts on the 
fundaments of the GO stocks. Therefore, the stock prices of the GO stocks do not continue to drop. Generally speaking, the market reaction of the GO stocks supports the PPH.

To sum up, the contradictory findings for the SAH stocks and the GO stocks suggest that investors in the Chinese stock market could moderately interpret the good news but underestimate the bad news.

\subsection{Event-Study Analysis: Category-Level Findings}

In this section, we further observe the impacts of the COVID-19 at the categorylevel. Table 3 reports the $C A R$ starting from the event date to the post- 60 trading days for the category of the GO stocks. As can be seen from this table, there exists significantly negative $C A R$ for the categories of Ride-hailing, Sports, and Travel in the following 20 days. However, Ride-hailing and Sports show an insignificant $C A R$ at the interval of $[0,30]$, which suggests a price reversal. These findings are in line with the overall findings for the GO stocks in Table 2. As for the Travel, although the $C A R$ is still significant at the interval of $[0,40],[0,50]$ and $[0,60]$, respectively, the value is decreased. In that sense, the market reaction of the GO stocks generally supports the PPH.

As for the SAH stocks, Table 4 reports the $C A R$ starting from the event date to the post-60 trading days for the category of the SAH stocks. As can be seen from this table, contrary to the overall findings, we find significantly negative returns on the event date for the categories of Beer, Cold Chain Logistics, and Dairy. However, the $C A R$ of the Cold Chain Logistics and Dairy reverses to be insignificant or significantly positive. The only exception is the category of Beer, which exhibits

Table 2 CAR in certain interval

\begin{tabular}{|c|c|c|c|c|}
\hline \multirow[t]{2}{*}{ Date } & \multicolumn{2}{|c|}{ SAH stocks } & \multicolumn{2}{|l|}{ GO stocks } \\
\hline & Mean & $P$ value & Mean & $P$ value \\
\hline 0 & -0.0010 & 0.6683 & -0.0128 & 0.0000 \\
\hline$[0,1]$ & 0.0093 & 0.0713 & -0.0340 & 0.0000 \\
\hline$[0,2]$ & -0.0029 & 0.6807 & -0.0895 & 0.0000 \\
\hline$[0,3]$ & 0.0205 & 0.0130 & -0.0738 & 0.0000 \\
\hline$[0,4]$ & 0.0492 & 0.0000 & -0.0688 & 0.0000 \\
\hline$[0,5]$ & 0.0712 & 0.0000 & -0.0494 & 0.0000 \\
\hline$[0,10]$ & 0.0235 & 0.0066 & -0.0517 & 0.0000 \\
\hline$[0,20]$ & 0.0657 & 0.0000 & -0.0269 & 0.0028 \\
\hline$[0,30]$ & 0.0717 & 0.0000 & 0.0243 & 0.0596 \\
\hline$[0,40]$ & 0.0836 & 0.0000 & 0.0105 & 0.4883 \\
\hline$[0,50]$ & 0.0657 & 0.0000 & -0.0117 & 0.4748 \\
\hline$[0,60]$ & 0.0428 & 0.0091 & -0.0426 & 0.0217 \\
\hline
\end{tabular}

This table reports the cumulative abnormal return $(C A R)$ around the event date. The definition of the $C A R$ is given in Eqs. (3) and (4). The starting date for the $C A R$ is 0 . The "Mean" denotes the $C A R$ on certain date. The " $P$ value" denotes the $p$ value of the t-test based on Kolari and Pynnönen (2010) 
Table 3 CAR in the category of GO stocks

\begin{tabular}{|c|c|c|c|c|c|c|}
\hline \multirow[t]{2}{*}{ Date } & \multicolumn{2}{|c|}{ Ride-hailing } & \multicolumn{2}{|l|}{ Sports } & \multicolumn{2}{|l|}{ Travel } \\
\hline & & & & & & \\
\hline & & & & & & \\
\hline 1] & & s & & & & 0.000 \\
\hline 2] & & & & & & 0.00 \\
\hline 0,3$]$ & -( & 0.0 & & 0.0 & & 0.0000 \\
\hline 0,4$]$ & -0.0 & 0 & 22 & 0.0 & & 0.000 \\
\hline 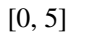 & & & & & & 00 \\
\hline 0,10$]$ & -0 & 0. & & & & 0.0000 \\
\hline$[0,20]$ & -0.03 & 0.0000 & $-c$ & 0.0 & - & 0.0000 \\
\hline$[0,30]$ & -0.0067 & 0.36 & -0.0 & 0.52 & & 0.0000 \\
\hline$[0,40$ & -0.0163 & & & & & 0.0000 \\
\hline 50] & -0 & 0.0 & & & & 0.0001 \\
\hline 0,60$]$ & 0.0120 & 0.0295 & -0.0055 & 0.4220 & -0.0259 & 0.0000 \\
\hline
\end{tabular}

This table reports the cumulative abnormal return $(C A R)$ around the event date. The definition of the $C A R$ is given in Eqs. (3) and (4). The starting date for the $C A R$ is 0 . The "Mean" denotes the $C A R$ on certain date. The " $P$ value" denotes the $p$ value of the t-test based on Kolari and Pynnönen (2010). The stocks in each category are given in "Appendix A"

significantly negative returns in the post-60 trading days. The $C A R$ of Cloud Office shows a completely different scenario, which has significantly positive returns during the entire sample period. Generally speaking, the results on the category of SAH stocks suggest the IDH. Besides, we also present the graphical illustration for the category-level findings in Figs. 3 and 4. The category-level findings of GO stocks in Fig. 3 show significant co-movements, while the category-level findings of SAH stocks in Fig. 4 reports distinct market reactions to the COVID-19.

\section{Conclusions}

Taking the outbreak of COVID-19 as the shock event, this paper empirically investigates the impacts of the COVID-19 on the Chinese stock market. By forming two groups of stocks, i.e., the stay-at-home (SAH) stocks, and the go-outsides (GO) stocks. We mainly find that: first, for the GO stocks, there exists a significantly negative return on the event date and the cumulative abnormal return reveals reversal pattern; second, for the SAH stocks, no significantly negative return is observed on the event date and the cumulative abnormal return continues to increase; and therefore, the reaction of the GO stocks supports the price pressure hypothesis, while the reaction of the SAH stocks supports the information diffusion hypothesis. Our results suggest that investors in Chinese stock market could moderately interpret the good news but underestimate the bad news.

Admittedly, our main research hypotheses are based on whether the market reaction to the COVID-19 is driven by information diffusion or price pressure. We would 


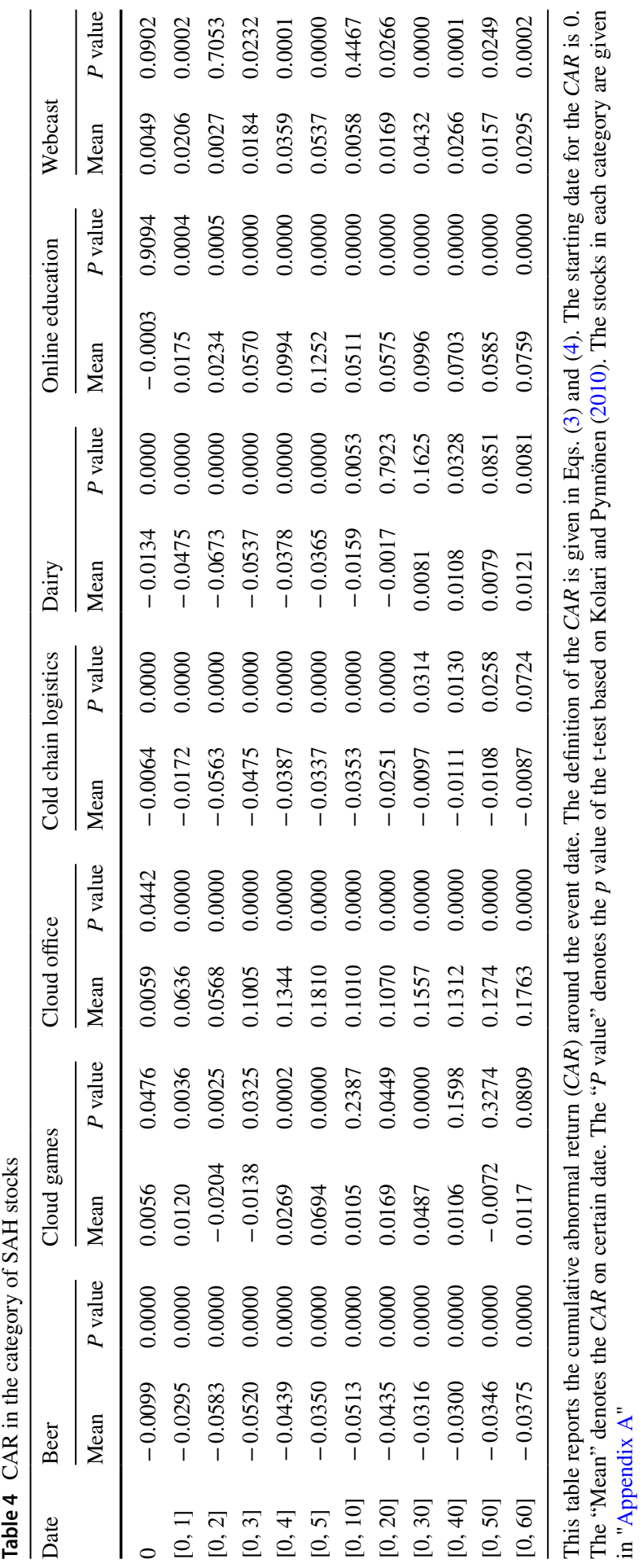




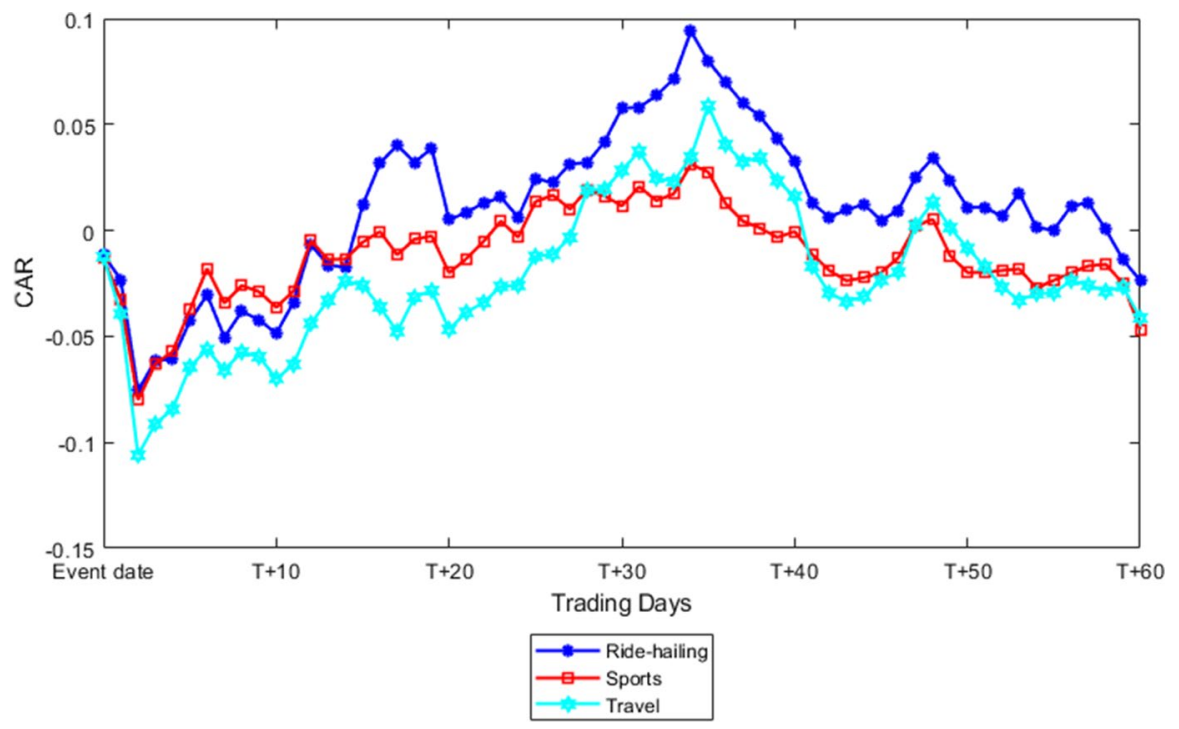

Fig. 3 Graphical illustration of category-level: GO-CAR

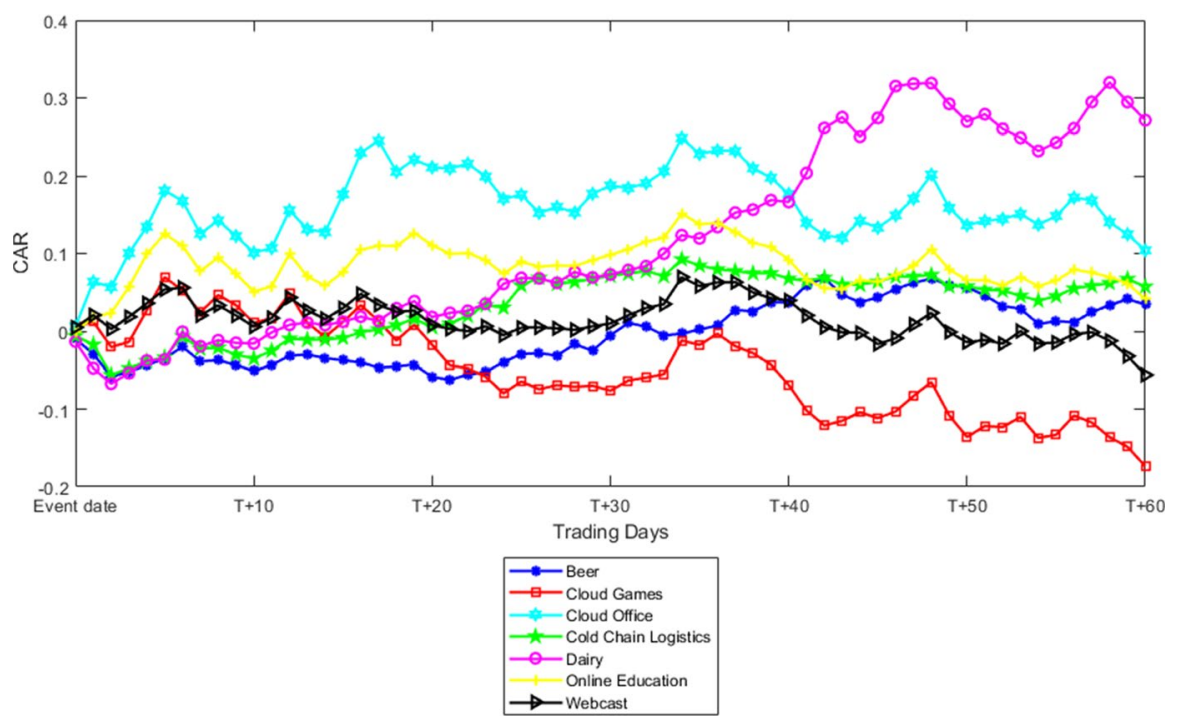

Fig. 4 Graphical illustration of category-level: SAH-CAR

like to remind scholars that other theories could also explain the observed price changes around the outbreak of the COVID-19. For example, in a recent study, Hu et al. (2020) show that investor attention could decrease the stock return co-movement. Xiong et al. (2020) further show that herding in the Chinese stock market is closely related to investor sentiment. In that sense, it would be extremely interesting 
to establish connections between investor behavior and market dynamics relying on the COVID-19 as a unique setting. We leave this for future research.

Acknowledgements This work is supported by the National Natural Science Foundation of China (71790594 and 71701150).

\section{Appendix A: Stay-at-Home Stocks and Go-Outsides Stocks}

See Tables 5, 6

Table 5 Stay-at-home stocks

\begin{tabular}{|c|c|}
\hline Category & Stock codes \\
\hline Cold chain logistics & $\begin{array}{l}\text { 600,113.SH, 600,125.SH, 600,336.SH, 600,410.SH, 600,597.SH, 600,650.SH, } \\
\text { 600,676.SH, 600,708.SH, 600,787.SH, 600,981.SH, 601,228.SH, 603,006.SH, } \\
\text { 603,186.SH, 603,187.SH, 603,339.SH, 603,882.SH, 000,039.SZ, 000,417.SZ, } \\
\text { 000,529.SZ, 000,530.SZ, 000,735.SZ, 000,811.SZ, 002,024.SZ, 002,086.SZ, } \\
\text { 002,158.SZ, 002,220.SZ, 002,352.SZ, 002,533.SZ, 002,639.SZ, 002,732.SZ, } \\
\text { 300,257.SZ }\end{array}$ \\
\hline Beer & $\begin{array}{l}\text { 600,108.SH, 600,132.SH, 600,543.SH, 600,573.SH, 600,600.SH, 603,076.SH, } \\
\text { 000,523.SZ, 000,729.SZ, 000,929.SZ, 002,461.SZ }\end{array}$ \\
\hline Dairy & $\begin{array}{l}\text { 600,127.SH, 600,191.SH, 600,300.SH, 600,359.SH, 600,419.SH, 600,429.SH, } \\
\text { 600,597.SH, 600,785.SH, 600,882.SH, 600,887.SH, 000,876.SZ, 002,329.SZ, } \\
\text { 002,505.SZ, 002,557.SZ, 002,570.SZ, 002,719.SZ, 002,732.SZ, 002,770.SZ, } \\
\text { 002,910.SZ, 300,106.SZ, 300,498.SZ }\end{array}$ \\
\hline Webcast & $\begin{array}{l}\text { 600,229.SH, 600,358.SH, 600,633.SH, 600,637.SH, 600,880.SH, 601,360.SH, } \\
\text { 601,519.SH, 603,189.SH, 000,839.SZ, 002,103.SZ, 002,127.SZ, 002,269.SZ, } \\
\text { 002,277.SZ, 002,280.SZ, 002,291.SZ, 002,292.SZ, 002,396.SZ, 002,445.SZ, } \\
\text { 002,467.SZ, 002,494.SZ, 002,517.SZ, 002,615.SZ, 002,699.SZ, 002,875.SZ, } \\
\text { 300,113.SZ, 300,133.SZ, 300,144.SZ, 300,251.SZ, 300,315.SZ, 300,413.SZ, } \\
\text { 300,418.SZ, 300,431.SZ, 300,467.SZ, 300,805.SZ }\end{array}$ \\
\hline Cloud office & $\begin{array}{r}\text { 600,225.SH, 600,804.SH, 603,000.SH, 603,039.SH, 603,660.SH, 603,918.SH, } \\
\text { 002,301.SZ, 002,417.SZ, 002,467.SZ, 002,474.SZ, 002,841.SZ, 300,047.SZ, } \\
\text { 300,051.SZ, 300,074.SZ, 300,250.SZ, 300,297.SZ, 300,352.SZ, 300,578.SZ, } \\
\text { 300,605.SZ, 300,608.SZ, 300,624.SZ, 300,628.SZ, 300,634.SZ, 300,730.SZ }\end{array}$ \\
\hline Cloud games & $\begin{array}{l}\text { 600,640.SH, 600,804.SH, 002,174.SZ, 002,425.SZ, 002,555.SZ, 002,602.SZ, } \\
\text { 002,699.SZ, 300,043.SZ, 300,113.SZ, 300,288.SZ, 300,356.SZ, 300,459.SZ, } \\
\text { 300,472.SZ, 300,494.SZ, 300,556.SZ }\end{array}$ \\
\hline Online education & $\begin{array}{c}\text { 600,035.SH, 600,229.SH, 600,355.SH, 600,373.SH, 600,551.SH, 600,576.SH, } \\
\text { 600,636.SH, 600,637.SH, 600,661.SH, 600,730.SH, 600,757.SH, 600,804.SH, } \\
\text { 601,098.SH, 601,801.SH, 601,928.SH, 601,999.SH, 603,268.SH, 603,528.SH, } \\
\text { 603,636.SH, 603,660.SH, 603,888.SH, 603,928.SH, 000,526.SZ, 000,607.SZ, } \\
\text { 000,695.SZ, 000,719.SZ, 000,810.SZ, 000,851.SZ, 000,917.SZ, 000,948.SZ, } \\
\text { 002,230.SZ, 002,261.SZ, 002,308.SZ, 002,315.SZ, 002,325.SZ, 002,348.SZ, } \\
\text { 002,362.SZ, 002,396.SZ, 002,467.SZ, 002,503.SZ, 002,512.SZ, 002,555.SZ, } \\
\text { 002,574.SZ, 002,607.SZ, 002,638.SZ, 002,659.SZ, 002,678.SZ, 002,730.SZ, } \\
\text { 002,841.SZ, 300,002.SZ, 300,010.SZ, 300,017.SZ, 300,020.SZ, 300,044.SZ, } \\
\text { 300,047.SZ, 300,050.SZ, 300,058.SZ, 300,074.SZ, 300,081.SZ, 300,089.SZ, } \\
\text { 300,167.SZ, 300,168.SZ, 300,170.SZ, 300,182.SZ, 300,192.SZ, 300,205.SZ, } \\
\text { 300,235.SZ, 300,248.SZ, 300,264.SZ, 300,271.SZ, 300,279.SZ, 300,282.SZ, } \\
\text { 300,287.SZ, 300,297.SZ, 300,329.SZ, 300,338.SZ, 300,359.SZ, 300,364.SZ, } \\
\text { 300,418.SZ, 300,559.SZ, 300,571.SZ, 300,645.SZ, 300,654.SZ, 300,688.SZ }\end{array}$ \\
\hline
\end{tabular}


Table 6 Go-outsides stocks

\begin{tabular}{ll}
\hline Category & Stock codes \\
\hline Ridehailing & 600,006.SH, 600,175.SH, 600,352.SH, 600,611.SH, 600,662.SH, 603,099.SH, 603,776. \\
& SH, 000,800.SZ, 000,980.SZ, 002,103.SZ, 002,279.SZ, 002,368.SZ, 002,405.SZ, \\
& 002,452.SZ, 002,627.SZ, 300,001.SZ, 300,170.SZ, 300,209.SZ \\
Sports & 600,018.SH, 600,052.SH, 600,136.SH, 600,146.SH, 600,158.SH, 600,358.SH, 600,555. \\
& SH, 600,633.SH, 600,655.SH, 600,814.SH, 600,881.SH, 601,966.SH, 603,081. \\
& SH, 603,099.SH, 603,129.SH, 603,555.SH, 603,908.SH, 000,002.SZ, 000,530. \\
& SZ,000,558.SZ, 000,796.SZ, 000,923.SZ, 000,935.SZ, 002,024.SZ, 002,027.SZ, \\
& 002,081.SZ, 002,105.SZ, 002,181.SZ, 002,224.SZ, 002,235.SZ, 002,264.SZ, 002,346. \\
& SZ, 002,395.SZ, 002,400.SZ, 002,482.SZ, 002,486.SZ, 002,489.SZ, 002,523.SZ, \\
& 002,626.SZ, 002,639.SZ, 002,694.SZ, 002,701.SZ, 002,776.SZ, 002,780.SZ, 002,832. \\
& SZ, 002,858.SZ, 002,899.SZ, 300,005.SZ, 300,043.SZ, 300,133.SZ, 300,162.SZ, \\
& 300,269.SZ, 300,280.SZ, 300,291.SZ, 300,431.SZ, 300,526.SZ, 300,651.SZ \\
& 600,054.SH, 600,088.SH, 600,138.SH, 600,239.SH, 600,258.SH, 600,358.SH, 600,555. \\
& SH, 600,593.SH, 600,606.SH, 600,640.SH, 600,662.SH, 600,706.SH, 600,749. \\
& SH, 600,754.SH, 601,007.SH, 601,888.SH, 603,099.SH, 603,136.SH, 603,199. \\
& SH, 603,869.SH, 000,069.SZ, 000,430.SZ, 000,524.SZ, 000,610.SZ, 000,620.SZ, \\
& 000,681.SZ, 000,796.SZ, 000,802.SZ, 000,863.SZ, 000,888.SZ, 000,917.SZ, 000,978. \\
& SZ, 001,979.SZ, 002,033.SZ, 002,059.SZ, 002,071.SZ, 002,146.SZ, 002,159.SZ, \\
& 002,310.SZ, 002,431.SZ, 002,485.SZ, 002,489.SZ, 002,596.SZ, 002,627.SZ, 002,694. \\
& SZ, 002,707.SZ, 300,005.SZ, 300,144.SZ, 300,178.SZ \\
\hline &
\end{tabular}

\section{References}

Al-Awadhi, A. M., Alsaifi, K., Al-Awadhi, A., \& Alhammadi, S. (2020). Death and contagious infectious diseases: Impact of the COVID-19 virus on stock market returns. Journal of Behavioral and Experimental Finance, 27, 100326.

Albert, R. L., Jr., \& Smaby, T. R. (1996). Market response to analyst recommendations in the "dartboard" column: the information and price-pressure effects. Review of Financial Economics, 5(1), 59-74.

Barber, B. M., \& Loeffler, D. (1993). The "Dartboard" column: Second-hand information and price pressure. Journal of Financial and Quantitative Analysis, 28(2), 273-284.

Berkman, H., Jacobsen, B., \& Lee, J. B. (2011). Time-varying rare disaster risk and stock returns. Journal of Financial Economics, 101(2), 313-332.

Boehmer, E., Masumeci, J., \& Poulsen, A. B. (1991). Event-study methodology under conditions of event-induced variance. Journal of Financial Economics, 30(2), 253-272.

Bourdeau-Brien, M., \& Kryzanowski, L. (2017). The impact of natural disasters on the stock returns and volatilities of local firms. Quarterly Review of Economics and Finance, 63, 259-270.

Brown, S. J., \& Warner, J. B. (1985). Using daily stock returns: The case of event studies. Journal of Financial Economics, 14(1), 3-31.

Chang, S.-C., Chen, S.-S., Chou, R. K., \& Lin, Y.-H. (2012). Local sports sentiment and returns of locally headquartered stocks: A firm-level analysis. Journal of Empirical Finance, 19(3), 309-318.

Chesney, M., Reshetar, G., \& Karaman, M. (2011). The impact of terrorism on financial markets: An empirical study. Journal of Banking \& Finance, 35(2), 253-267.

Edmans, A., GarcÍA, D., \& Norli, Ø. (2007). Sports sentiment and stock returns. Journal of Finance, 62(4), 1967-1998.

Hu, Y., Li, X., \& Shen, D. (2020). Attention allocation and international stock return comovement: Evidence from the Bitcoin market. Research in International Business and Finance, 54, 101286.

Kaplanski, G., \& Levy, H. (2010). Sentiment and stock prices: The case of aviation disasters. Journal of Financial Economics, 95(2), 174-201.

Kolari, J. W., \& Pynnönen, S. (2010). Event study testing with cross-sectional correlation of abnormal returns. Review of Financial Studies, 23(11), 3996-4025. 
Lepori, G. M. (2015). Investor mood and demand for stocks: Evidence from popular TV series finales. Journal of Economic Psychology, 48, 33-47.

Li, X., Shen, D., \& Zhang, W. (2018). Do Chinese internet stock message boards convey firm-specific information? Pacific-Basin Finance Journal, 49, 1-14.

Liang, B. (1999). Price pressure: evidence from the "Dartboard" column. Journal of Business, 72(1), 119-134.

Papakyriakou, P., Sakkas, A., \& Taoushianis, Z. (2019). The impact of terrorist attacks in G7 countries on international stock markets and the role of investor sentiment. Journal of International Financial Markets, Institutions and Money, 61, 143-160.

Shan, L., \& Gong, S. X. (2012). Investor sentiment and stock returns: Wenchuan earthquake. Finance Research Letters, 9(1), 36-47.

Xiong, X., Wang, C., \& Shen, D. (2020). Market participation willingness and investor's herding behavior: evidence from an emerging market. Asia-Pacific Financial Markets. https://doi.org/10.1007/ s10690-020-09302-8.

Zhang, W., Li, X., Shen, D., \& Teglio, A. (2016a). R ${ }^{2}$ and idiosyncratic volatility: Which captures the firm-specific return variation? Economic Modelling, 55, 298-304.

Zhang, Y., Song, W., Shen, D., \& Zhang, W. (2016b). Market reaction to internet news: Information diffusion and price pressure. Economic Modelling, 56, 43-49.

Zhang, Y., Zhang, Y., Shen, D., \& Zhang, W. (2017). Investor sentiment and stock returns: Evidence from provincial TV audience rating in China. Physica A: Statistical Mechanics and its Applications, 466, 288-294.

Publisher's Note Springer Nature remains neutral with regard to jurisdictional claims in published maps and institutional affiliations. 